\title{
Irony and the Standard Pragmatic Model
}

\author{
Istvan Palinkas ${ }^{1}$ \\ ${ }^{1}$ Doctoral School of Linguistics, University of Debrecen, Hungary \\ Correspondence: Istvan Palinkas, 11, Október 23. tér, 4700 Mátészalka, Hungary. Tel: 36-44-314-410. E-mail: \\ palinkasistvan@yahoo.com
}

Received: January 31, 2013 Accepted: July 10, 2013 Online Published: September 23, 2013

doi:10.5539/ijel.v3n5p14

URL: http://dx.doi.org/10.5539/ijel.v3n5p14

\begin{abstract}
The article provides a criticism of the traditional view of irony. First, an outline of the model will be presented, placing particular emphasis on one of its key assumptions that when irony is understood, the ironist means the opposite of what he says.

The paper evaluates the above supposition by providing examples of irony in which the opposite of the speaker's meaning could be interpreted in terms of two different types of negation: predicate and propositional.

In conclusion, I propose that it might be impossible to define the exact opposite of what a speaker says. Thus, the traditional view of irony is incomplete and should be treated with precaution.
\end{abstract}

Keywords: irony, opposite meaning, predicate, propositional, traditional

\section{Introduction}

In much of our everyday talk we occasionally use indirect forms of communication to achieve some pragmatic effect. One such rhetorical device is verbal irony, which is most often used to express some negative evaluation on the part of the speaker. For example, in a situation where a couple has planned a trip for the weekend for which the weather forecaster predicted nice weather but it proved otherwise, the wife could ironically express her disappointment and say "What beautiful weather we have today".

In linguistics, irony returns as a topic related with the Gricean theory of inferences in the 1970s. According to the Standard Pragmatic Model (Grice, 1975, 1978), in the representation of irony, the 'decoder' (i.e., the hearer) first needs to process the literal meaning of the ironically intended remark. Then, this meaning is tested against the context. Once the hearer has realised that there is an apparent violation of the maxim of quality, stating that the speaker should make his contribution to the conversation one that is true, he needs to find some alternative, figurative interpretation. The process to retrieve the intended meaning involves inferential reasoning in which the hearer infers the opposite of what the speaker has literally said.

In relation to 'oppositeness of (literal) meaning', the Standard Pragmatic Model has been criticised on the following grounds: a) Coulson (2005), Gibbs and O'Brien (1991), and Kaufer (1981) argue that it might be challenging to find the exact opposite of the literal meaning of an ironically intended remark, b) Coulson (2005), Currie (2006) and Giora et al. (2005) make mention of cases in which the ironic speaker does not mean the opposite of what he says, and c) Wilson (2006) and Wilson and Sperber (2004) take issue with the Gricean approach to irony and claim that it is difficult to see why a rational speaker would choose an utterance whose meaning is the opposite of the one he intends to communicate.

The main objective of this paper is to challenge the Standard Pragmatic Model of irony in relation to the first of the above criticisms: it can occasionally be difficult to define the exact opposite of an ironic utterance. The reasoning in this study is different from that in the literature, as the potential multiplicity of ironic meanings will be justified through making a distinction between the predicate- and the propositional negation of the literal meaning of an ironic remark. Before delving into the analysis, however, let us consider the origin of such an approach (Haverkate, 1990) and the difficulties that source might possibly encounter.

\section{Haverkate on the Opposite of What is Literally Said: A Review}

In an attempt to refine the traditional view of irony in relation to 'oppositeness of (literal) meaning', Haverkate (1990) aims to specify the type of negation that brings the hearer closer to the intended (figurative) meaning. For his purposes, the author analyses the following example: 
(1) Well, a charming couple you are! (said ironically to a couple who live together but do not speak to each other)

Haverkate argues that in order to properly analyse the opposite meaning(s) of (1), it is necessary to distinguish cases of semantic opposition, in which a) the proposition is negated (as in (1a)), or b) the predicate or one of its components is negated (as indicated in (lb)):

(1a) Well, you are not a charming couple!

(1b) Well, you are a boring couple!

As Haverkate explains, in (1a) the negation affects the whole proposition, establishing a logical opposition with the affirmative proposition of (1). As opposed to this, in (1b) the predicate 'boring couple' does not form a logical but a lexical opposition with the corresponding predicate of (1). Further, what (1a) literally expresses is simply that the speaker does not have a positive impression of the interpersonal relation of his interlocutors. Therefore, since (1a) does not reflect a negative evaluation on the part of the speaker, irony is not expressed in that negation. On the other hand, as 'boring couple' explicitly specifies the criticism of the speaker, (1b) can be considered the sort of opposite (of (1)) that establishes an ironic interpretation.

The conclusion Haverkate reaches is that in order to properly analyse the figurative implication of assertions such as (1), the opposite of what is literally said should not be interpreted in terms of propositional negation. Rather, in those cases, irony might be better understood in relation to the opposite lexical meaning of the predicate.

In my view, however, Haverkate's suggestions run into the following difficulties: he suggests that, since "Well, you are not a charming couple" does not express a negative evaluation, it cannot be considered a non-ironic paraphrase of (1). I disagree with this assertion and argue that (1a) can also have an ironic meaning. In this case, however, the irony comes from the fact that the ironic remark in (1) induces a conflicting conceptual organisation on the part of the comprehender: it goes against our folk understanding (of marriage) that a couple who do not speak to each other should be considered 'charming'. This very conflict alone then drives the hearer to understand (1) as a figurative statement.

Second, Haverkate argues that "Well, you are a boring couple" can be considered a non-ironic paraphrase of (1). The definition of meaning (in the semantic sense) is admittedly highly theory-dependent but no matter how it is defined, apart from Haverkate perhaps no semanticist would argue that the meaning of the word 'charming' changes to something like 'boring' when used ironically. (This is in contrast to the case of, for example, metaphor, when the meaning of, say, 'defend' can really be argued to be different in 'defend a fort' and 'defend a dissertation'.) Thus, I would not say that in the ironic use of 'charming' the inference that the couple is 'boring' is actually communicated by the speaker.

To conclude, Haverkate's (1990) intention to refine the Standard Pragmatic Model of irony in relation to oppositeness of meaning appears to have some problems. In spite of this, however, Haverkate has introduced into linguistic theory a novel way of thinking about this figurative phenomenon: the representation of irony can be discussed in relation to both the predicate- and the propositional negations of what a speaker says.

\section{Predicate- and Propositional Negation, and the Representation of Irony}

The previous section showed that irony was discussed in terms of different sorts of negation even in the 1990s. In contrast to Haverkate (1990), however, my intention is not to affirm that only one type of opposition (the predicate but not the propositional) plays a part in the representation of irony. Rather, I argue that the understanding of ironic statements can occasionally be interpreted in relation to both the predicate- and the propositional negations of the speaker's literal meaning. This claim will now provide an arena to criticise the Standard Pragmatic Model of irony. Furthermore, Haverkate discusses the opposite of predicates in terms of lexical meaning, arguing - mistakenly in my view - that the meaning of 'charming' changes to something like 'boring' when used ironically. Instead, I claim that the opposite of what a speaker says should be considered in relation to 'literal meaning', which could be regarded as 'what the speaker would normally be expected to mean/communicate on the basis of the meanings of the words he is using'. Thus, when I identify different opposites of an ironically intended remark, I do so against the literal meaning defined above.

As a starting point for the discussion of the versatile nature of opposite meaning of ironically intended remarks, let us consider Lyons (1995), who suggests that predicate negation is obviously not equivalent to the negation of the whole proposition. Consider (2) below, whose potential opposites are presented in (2a) and (2b):

(2) John is friendly. 
(2a) John is not friendly. (contradictory to John is friendly)

(2b) John is unfriendly. (contrary to John is friendly)

While (2a) describes the passive absence of a positive attribute, in (2b) John is actively hostile and behaves in an unfriendly manner, as opposed to merely refraining from acting in a friendly way.

According to Lyons (1995), (2b) expresses a proposition that is not just the 'contradictory' of the proposition expressed by "John is friendly" but its 'contrary'. Hence, (2b) above is not simply the negation of (2); it means, as stated, that John is actually malicious. Furthermore, in standard logical terminology, one proposition is the contradictory of another if it is impossible for both of them to be true and for both to be false. One proposition is the contrary of another if both cannot be true, though they may both be false. Thus, the relation between (2) and (2b) is one of contrariness since (as opposed to the relation between (2) and (2a)) in this case both may be false. That is, it is quite possible for John to be neither friendly nor unfriendly (Lyons, 1995). This means that John may refrain from acting in a friendly way though he may not be actively hostile. Let us now examine (2) as it is said in a particular situation, analyse its semantic and pragmatic attributes in context and see how these two sets of features are related.

Imagine a scenario in which Tom and Pete are close friends. One day, a new neighbour (John) is about to move in the flat which is adjacent to Pete's. Tom happens to know the newcomer and says to Pete: "You need not worry, John is friendly". However, after a couple of weeks' time Tom meets his friend again, and the following exchange occurs:

Tom: "Hi Pete, how's things?"

Pete: "Don't ask!"

Tom: "What's the matter?"

Pete: "My new neighbour ... you know ..."

Tom: "No. What?"

Pete: “... that John. Last time you told me that he was a good guy. Well, he [is] friendly." (said in an ironic tone) (emphasis added to 'is')

Tom: "Is he giving you grief?"

Pete: "Is he ever! He refuses to trim the hedge on his boundary with us and it is blocking the sunlight from my vegetable patch. Up until now he has just ignored me but this morning he started throwing insults and threats!"

To: "Oh dear!"

From the beginning of the conversation it might be obvious to Tom that Pete is disappointed about the new neighbour. However, when Pete says in an ironic tone that "Well, he [is] friendly", without providing any further details, Pete's remark (depending on whether the predicate or the proposition is negated) could be pragmatically 'noisy', since it is fairly ambiguous between its active and passive understandings: hostility, and (simply) lack of a positive attribute (that is, friendliness), respectively. Thus, one reason Tom asks further questions might be to know in what sense Pete is using the irony. In other words, Pete's ironic remark shows use of an opposite meaning in that both the passive absence of a positive attribute (i.e., propositional negation) and the idea of hostile behaviour (i.e., predicate negation) could be considered potential opposites of 'friendly'; these negations might constitute to what is generally called 'pragmatic implication'. The Standard Pragmatic Model, however, cannot explain this example of irony, exactly due to the multiplicity of opposite meanings.

A consideration of the differences between the direct, scalar negation of propositions and the non-scalar negation of predicates provides further evidence in support of the multi-dimensional nature of 'the opposite':

(3) The coffee is hot.

(3a) The coffee is not hot.

(3b) The coffee is cold.

While (3b) expresses the diametric opposite of what we normally mean in (3), the negated proposition 'not hot' in (3a) generally means 'less than hot' rather than 'cold' (see also Horn 1989). That is, as Giora (1995) argues, direct negation ('not hot') invokes weaker interpretations whereby only one value on a spectrum (that is 'hotness', in this case) is negated while "the rest is affirmed" (Giora, 1995, p. 241) that is, left open to interpretation.

However, I might note in passing that Giora (1995) seems to be confused in her explanation, since her reasoning 
that in case of direct negation (not hot) the core proposition (that is, that the coffee is 'hot') is discredited and that "the rest is affirmed" (where the domain of discourse extends all along to 'cold', in my view) implies that 'the coffee is cold' is also included as a possible opposite interpretation of (3a). In a rather inconsistent fashion, however, Giora (1995, p. 241) argues that "the explicitly negated expression [hot] functions as the central member of the set whose negation allows for the less central [or approximate] members [but not the distant marginal ones, as Giora also explains] to take over". That is, in Giora's view, the 'distant marginal interpretations' are discredited as possible understandings when a statement is explicitly negated. In this view, the interpretation of (3a) excludes the slightest possibility that the coffee could by any chance be 'cold'. I disagree with Giora on this point and argue that in such continuums, although 'not $X$ ' does not necessarily imply ' $\mathrm{Y}$ ', it does not exclude ' $\mathrm{Y}$ ' either. Thus, 'not hot coffee', for instance, can be 'cold', but not simply by virtue of being not 'hot'.

Despite the above obscurity that I find in Giora's explication on negation, I see the following approach (which can also be deduced from Giora's discussion of 'the opposite') as worthy of note: the opposite of scalar concepts can, occasionally, be accomplished in at least two different ways: via direct (or propositional) negation (not hot) and through predicate negation (cold). This is a dichotomy that any theory operating along the notion of opposite meaning should not leave unaccounted for.

Consider the following situation in which Mike invites his colleague, Jane, for a cup of hot black coffee from a vending machine. Mike does not drink coffee, he drinks iced tea. There seems to be some problem with the machine but they do not know. When Jane's coffee turns out to be anything but hot, the following exchange occurs:

Jane: "Mike, you promised a cup of [hot] black coffee." (emphasis added to 'hot')

Mike: "Yeah. What's up with it?"

Jane: "It's [really] hot." (in an ironic, playful tone) (emphasis added to 'really')

In the above situation, the coffee is probably not to Jane's liking. The ironic "It's [really] hot", however, might not indicate to Mike whether the coffee is cold or if it is somewhere between the two extremes of the temperature spectrum. Thus, this example of irony might make use of opposite meaning in the sense that both 'cold' and 'lukewarm' could be considered potential opposites of 'hot'. However, the fact that the opposite of "It's [really] $h o t$ " can be interpreted in terms of both its predicate- and its propositional negation, the Standard Pragmatic Model has difficulty explaining Jane's utterance.

Another principle to consider in determining 'the opposite' of an ironically intended remark in terms of its predicates and propositions concerns the specification of the 'schema' used for encoding negations. Take the following example:

(4) Tom is not guilty.

There seem to be (at least) two alternate theories, working under different assumptions, that explain the representation of (4). According to the 'schema-plus-tag' model (Clark \& Chase, 1972) the core supposition ("Tom is guilty", in our case) is processed as a cognitive unit, which is then marked with a negation tag, resulting in (4) above.

The 'fusion' model (see, for example, Horn, 1989; Lyons, 1995), on the other hand, states that the core of a negated message and the negation marker are integrated into one meaningful unit, thus transforming the negation into an affirmation. Hence, the message in (4) may be transformed into its affirmative counterpart and coded as:

(5) Tom is innocent (Note 1).

The nature of the inferences that are facilitated by these competing models is different. The schema-plus-tag model assumes that "Tom is not guilty" is processed within the schema referring to the negatively biased core supposition, 'guilt'. In contrast, according to the fusion model, a negation-congruent schema ('innocence') is activated. This distinction is highly significant, since, as Mayo et al. (2004, p. 435) argue, "not only do the two schemas have opposite meanings, they are also embedded in markedly different associative networks".

I assume that opposite meaning might play some role in the representation of ironic examples like "Tom is guilty". However, there is evidence that the negation of this example presupposes at least two different processing mechanisms: one proceeding along the cognitive model of 'guilt' and one along the positive associative network of 'innocence'. Without addressing this duality in an experimental setting, however, one could only guess which of the two negations is activated in the comprehension process - and any such speculation is beyond the scope of this paper. Thus, The Standard Pragmatic Model is incomplete in the sense 
that it also does not explain the parameters and conditions underlying the activation of the different processing schemas that give the essence of the emergent meaning.

\section{Summary}

The paper shows that earlier attempts at discussing irony in terms of predicate- and propositional negation should be revised, since irony should not be discussed only in relation to the negation of the predicate (of an ironic utterance). That is, the opposite meaning of an ironically intended remark can occasionally be interpreted in relation to both the predicate- and the propositional negations of what an ironist literally says. As a result, the assumption established by the Standard Pragmatic Model that an ironic speaker means the opposite of what he says should be considered with care and caution.

\section{References}

Clark, H., \& Chase, W. (1972). On the process of comparing sentences against pictures. Cognitive Psychology, 3 , 472-517. http://dx.doi.org/10.1016/0010-0285(72)90019-9

Coulson, S. (2005). Sarcasm and the space structuring model. In S. Coulson, \& B. Lewandowska-Tomaszczyk (Eds.), The literal and the nonliteral in language and thought (pp. 129-144). Berlin: Peter Lang.

Currie, G. (2006). Why irony is pretence. In S. Nichols (Ed.), The architecture of the imagination (pp. 111-133). Oxford: Oxford University Press. http://dx.doi.org/10.1093/acprof:oso/9780199275731.003.0007

Gibbs, R., \& O’Brien, J. (1991). Psychological aspects of irony understanding. Journal of Pragmatics, 16, 523-530. http://dx.doi.org/10.1016/0378-2166(91)90101-3

Giora, R. (1995). On irony and negation. Discourse Processes, 19, 239-264. http://dx.doi.org/10.1080/01638539509544916

Giora, R., Fein, O., Ganzi, J., \& Alkeslassy Levi, N. (2005). On negation as mitigation: The case of negative irony. Discourse Processes, 39, 81-100. http://dx.doi.org/10.1207/s15326950dp3901_3

Grice, P. (1975). Logic and conversation. In P. Cole, \& J. Morgan (Eds.), Syntax and semantics: Speech acts (Vol. 3, pp. 41-58). New York: Academic Press.

Grice, P. (1978). Further notes on logic and conversation. In P. Cole (Ed.), Syntax and semantics: Pragmatics (Vol. 9, pp. 113-127). New York: Academic Press.

Haverkate, H. (1990). A speech act analysis of irony. Journal of Pragmatics, 14, 77-109. http://dx.doi.org/10.1016/0378-2166(90)90065-L

Horn, L. (1989). A natural history of negation. Chicago: University of Chicago Press.

Kaufer, D. (1981). Understanding ironic communication. Journal of Pragmatics, 5, 495-510. http://dx.doi.org/10.1016/0378-2166(81)90015-1

Lyons, J. (1995). Linguistic semantics: An introduction. Cambridge: Cambridge University Press. http://dx.doi.org/10.1017/CBO9780511810213

Mayo, R., Schul, Y., \& Burnstein, E. (2004). "I am not guilty" vs "I am innocent”: Successful negation may depend on the schema used for its encoding. Journal of Experimental Social Psychology, 40, 433-449. http://dx.doi.org/10.1016/j.jesp.2003.07.008

Wilson, D. (2006). The pragmatics of verbal irony: Echo or pretence? Lingua, 116, 1722-1743. http://dx.doi.org/10.1016/j.lingua.2006.05.001

Wilson, D., \& Sperber, D. (2004). Relevance theory. In L. R. Horn, \& G. Ward (Eds.), The handbook of pragmatics (pp. 607-632). Oxford: Blackwell.

\section{Note}

Note 1. Mayo et al. (2004) have made a start in this direction of research and found that when a schema that accommodates the meaning of the original negation is not readily available (as, for example, in 'Peter is responsible'), a negated message facilitates negation-incongruent associations, in line with predictions of the schema-plus-tag model. When receivers, on the other hand, have a schema to accommodate the meaning of the negation as a whole (as in 'Kate is honest' where, as a result of its being bi-polar, the concept of 'honesty' inherently includes the opposite in the form of the negative associative network of 'dishonesty'), the negation should be encoded in line with the fusion model. 


\section{Copyrights}

Copyright for this article is retained by the author(s), with first publication rights granted to the journal.

This is an open-access article distributed under the terms and conditions of the Creative Commons Attribution license (http://creativecommons.org/licenses/by/3.0/). 